\title{
A rare case of pregnancy complicated by snake bite
}

\author{
Rita Mittal*, Bishan Dhiman, Nishi Sood, Shilpa Sood
}

Department of Obstetrics \& Gynaecology, KNSHM\&C, IGMC, Shimla, Himachal Pradesh, India

Received: 24 October 2015

Accepted: 12 December 2015

\section{*Correspondence:}

Dr. Rita Mittal,

E-mail: mittaldrrita@gmail.com

Copyright: (C) the author(s), publisher and licensee Medip Academy. This is an open-access article distributed under the terms of the Creative Commons Attribution Non-Commercial License, which permits unrestricted non-commercial use, distribution, and reproduction in any medium, provided the original work is properly cited.

\section{ABSTRACT}

Though snake bite is not common among pregnant women, however, the obstetrical consequences are severe and related to severity of envenomation. Little is known about the toxic effects and optimal management of snake envenoming because of rarity of cases. That was the main purpose of presenting this case.

Keywords: Abruptio placentae, Coagulopathy, Envenomation

\section{INTRODUCTION}

Worldwide occurrence of snake bite in pregnancy is rare, however, the obstetric consequences are severe and related to severity of envenomation. Snakes may be poisonous or non-poisonous. Only about $400(15 \%)$ of 3000 snake species worldwide inject venom. Most snake bites are innocuous and are delivered by non-poisonous snakes. ${ }^{1}$

\section{CASE REPORT}

30 years, $\mathrm{G}_{8} \mathrm{P}_{4+3}$ was admitted on 11 June 2014 with the history of:

- Amenorrhea $\times 7$ months

- Snake bite 3 days back

- $\mathrm{BPV} \times 7 \mathrm{hr}$

Bleeding was painless, spontaneous, dark red in colour \& heavy with passage of clots. Patient gave H/O snake bite on left hand on 8 June 2014 while working in fields, for which she was treated in IGMC on 09/06/2014. On examination her left hand was swollen with diffuse swelling extending up to left shoulder. Dorsum of left hand had bite marks at base of thumb. There was $\mathrm{H} / \mathrm{O}$ passage of dark coloured urine while no H/O bleeding from any other site or weakness in any of the limbs.

Patient was unbooked case and had no antenatal complication till the present complaint. There was nothing significant in past and family history. On GPE, she was markedly pale though her vitals were stable. On P/A examination- Abdomen was uniformly distended with height of uterus $=26$ weeks with breech presentation. Uterus was mildly tense \& tender with adequate liquor and FHS was $130 \mathrm{bpm}$. Local examination revealed external genitalia to be soiled with blood.

On P/S exam: There were clots in vagina with profuse bleeding through os.

$\mathrm{Her} \mathrm{Hb}$ was $8 \mathrm{gm} \%$ and rest of the investigations were normal. Decision for hysterotomy was taken.

\section{Operative findings}

There was e/o couvelaire uterus. Lower uterine segment was not well formed while liquor was blood stained and there was $30-40 \%$ abruption of placenta and $100 \mathrm{gm}$ of retroplacental clots with approx. blood loss $-1000 \mathrm{ml}$. 


\section{Baby notes}

Preterm female child with birth wt. of $600 \mathrm{gm}$ and no gross congenital anomalies and APGAR score of 3/5 was extracted. Baby had generalized petechial haemorrhages. Baby died after about 3 hours.

Postoperatively patient was given 2 units of whole blood transfusion and 1 unit of Fresh frozen plasma (FFP). She remained well for 2 days, but on $3^{\text {rd }}$ POD she started bleeding from wound site which was fresh and excessive. On examination her vitals were stable, Uterus was 20-22 weeks size and well retracted while bleeding per vaginum was minimal. Patient was catheterized and $300 \mathrm{cc}$ of haemorrhagic urine was drained. USG and Paracentesis showed haemoperitoneum while lab Investigations were as below:

$$
\begin{aligned}
& \mathrm{Hb}-5 \mathrm{~g} / \mathrm{dl} \downarrow, \mathrm{Hct}-15.2 \%, \mathrm{Plt}-1,70,000 / \mu \mathrm{L}, \\
& \mathrm{WBC}-6900 / \mu \mathrm{L}, \mathrm{RFT}=\mathrm{N}, \mathrm{LFT}=\mathrm{N}
\end{aligned}
$$

\section{Coagulation Profile}

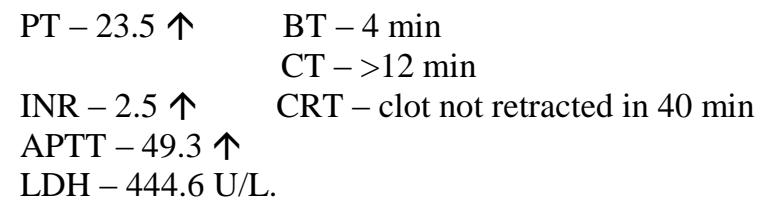

Keeping possibility of internal haemorrhage, she was prepared for re-exploration.

\section{Operative findings}

There was e/o haemoperitoneum [about 3L] with oozing from both uterine angles and uterovesical fold. Haemostatic suturing of the uterine incision with peritoneal toileting was done with infusion of 2 units of whole blood and 1 unit of FFP.

Medicine opinion was taken and probable diagnosis of DIC was made and treatment for the same in the form of blood components was advised. Patient was stable after 2 units of whole blood and 1 unit of FFP. But on $3^{\text {rd }}$ POD of re-exploration she again started having heavy bleeding from wound site along with abdominal distension and deranged coagulation profile.

\section{$\mathrm{BT}-5 \mathrm{~min}, \mathrm{CT}-6 \mathrm{~min} 30 \mathrm{sec}$ and CRT $>40 \mathrm{~min}$}

Meanwhile the records of her treatment at IGMC were sought which revealed that she had left the IGMC against medical advice and thus she didn't get the ANTISNAKE Venom [ASV] as advised by the medicine deptt. Medicine opinion was sought again and possibility of late manifestations of snake bite/bleeding disorders was kept. Patient was advised ASV and shifted to IGMC, where ASV was given and she recovered.

\section{DISCUSSION}

Pardal et al did a preliminary study to evaluate the frequency of snake bites during pregnancy as well as their obstetrical consequences. ${ }^{2}$ During a $5 \mathrm{yr}$ period, total 157 patients presented with $\mathrm{H} / \mathrm{o}$ snake bite and $8(5 \%)$ were pregnant, $6(75 \%)$ were in first trimester and $2(25 \%)$ were in second trimester. Severe obstetrical complication occurred in $3(37.5 \%)$ and mild manifestation occurred in $5(62.5 \%)$.

\section{Aetiopathogenesis}

Snake venom is a highly concentrated, clear, amber coloured digestive juice of the snake. Its toxic properties are due to proteolytic enzymes, phosphotidases and neurotoxins. The venom coagulates fibrinogen and prothrombin and converts them into fibrilar gel and thrombin with the resultant effect of liberation of histamines leading to dissolution of blood vessels and release of erythrocytes and serum in the tissues.

Phosphotidases cause haemolysis and toxic effects on heart and circulation. There is haemorrhage from the lungs due to damage to capillary endothelium and neurotoxins produce a curare like effects as well as paralysis

The toxin present in the snake venom is a coagulating active agent, which, when injected into the maternal circulation, even in small amount, soon reaches the placental circulation. The venom apparently crosses the placenta in amounts that can cause systemic poisoning in the fetus even without evidence of envenomation in the mother. The coagulation fraction gradually leads to a consumptive coagulopathy by fibrinogen depletion.

Finally the blood reaches the deciduo-placentary cleavage zone and starts its dissociation leading to abruptio placentae.

In the above study, all $8(100 \%)$ patients presented with vaginal bleeding, pain and local oedema, 50\% reported ascendant oedema, $37.5 \%$ with gingival bleeding, headache and dizziness. Fetal demise occurred in one. ${ }^{2}$

In another study by Dunnihoo et al till 1992, total 50 such cases were reported. ${ }^{3}$ They found that snake bite carries with it a high risk of fetal wastage of $43 \%$ and maternal mortality of $10 \%$. Venom causes defibrination of blood and leads to bleeding throughout the body.

In another study by Langley R L et al (2010) from South Africa, India and Srilanka, pregnant women have accounted for $0.4 \%-1.8 \%$ of hospitalized snakebite cases. ${ }^{4}$

Several mechanisms have been proposed to explain fetal death or abortions after snake bite, due to fetal anoxia because of: 
- Maternal shock because of fear

- Direct effect of venom

- Haemorrhages into placenta and uterine wall causing abruptio placentae due to coagulopathy.

- Venom induced preterm labour

- Pyrexia

- Cytokine release

- Venom may act directly on uterine muscle or may act indirectly by causing release or potentiating the effect of bradykinins on uterine muscles. These all will lead to fetal compromise or even intrauterine death along with maternal shock.

- Further there is potential risk of anaphylactic reaction with anti-snake venom.

\section{Treatment issues}

- Early gestational age and delay in the treatment suggests an unfavourable prognosis, however, the prognosis is better in third trimester. (thrombocytopaenia in first trimester)

- Treatment is a complex issue as simultaneous care has to be rendered to two patients.

- The specific treatment for snake envenomation is antisnake venom. Species specific ASV is the main stay of therapy. ASV is a biological product used in the treatment of venomous bites or stings. Antivenom is created by injecting a small amount of the targeted venom into an animal such as a horse, sheep, goat, or rabbit, the subject animal will undergo an immune response to the venom, producing antibodies against the venom's active molecule which can then be harvested from the animal's blood and used to treat envenomation. These can be

a) Monovalent: when they are effective against a given species venom.

b) Polyvalent: when they are effective against a range of species, or several different species at the same time.

- Most worrisome problem with ASV is the anaphylactic reaction. However, Antivenom therapy should not be withheld unless the risk of anaphylaxis outweighs the benefits.

- Venom exposure during pregnancy may also cause teratogenesis, foetal growth retardation or even mutagenesis.

- Most researchers recommend that the therapy in pregnant patients should be same as in nonpregnant.
- Nifedipine can be given for tocolysis but magnesium sulphate is contraindicated (neurotoxic).

- Other main stay of treatment is adequate availability of blood and its fractions. ${ }^{1}$

\section{CONCLUSIONS}

Snake bite [poisonous] carries high risk of fetal wastage of around $43 \%$ and maternal mortality rate of $10 \%$. The commonest adverse obstetrical events are vaginal bleeding, IUD, PTL and threatened abortion.

- All the cases are not reported, however, the more recent literature seems to show an improvement in both fetal and maternal outcome (20\% and 4-5\%) because of ASV.

Coagulating mechanism is disturbed leading to bleeding diathesis which may be recurrent and may not be totally preventable despite treatment.

Funding: No funding sources

Conflict of interest: None declared

Ethical approval: Not Required

\section{REFERENCES}

1. De-kaa NLP, Alao AK, Atabo A, Pitmang SL, Jombo GTA. Snake bite in a pregnant woman-a case survived. Asian Journal of Pharmaceutical and Health Sciences. 2012;2(4):440-1.

2. Pardal PPO, Mazzeo T, Pinheiro ACL. Snake bite in pregnancy: A preliminary study. Journal of Venomous Animals and Toxins. 1997;3(2).

3. Dunnihoo DR, Rush BM, Wise RB, Brooks GG, Otterson WN. Snake bite poisoning in pregnancy. A review of the literature. J Reprod Med. 1992;37(7):653-8.

4. Langley RL. Snake Bite During Pregnancy: A Literature Review. Wilderness \& Environmental Medicine. 2010;21(1):54-60.

Cite this article as: Mittal R, Dhiman B, Sood N, Sood S. A rare case of pregnancy complicated by snake bite. Int J Reprod Contracept Obstet Gynecol 2016;5:243-5. 